\title{
Electromyographic registration of diaphragmatic fatigue during sustained trunk flexion in cervical cord injured patients
}

\author{
C Sinderby $\mathrm{PhD},{ }^{1} \mathrm{P}$ Ingvarsson $\mathrm{MD},{ }^{2} \mathrm{~L}$ Sullivan $\mathrm{MD} \mathrm{PhD},{ }^{1}$ \\ I Wickström $\mathrm{MD} \mathrm{PhD},{ }^{3} \mathrm{~L}$ Lindström $\mathrm{PhD}^{4 *}$ \\ Departments of ${ }^{I}$ Neurosurgery, ${ }^{2}$ Neurology, ${ }^{3}$ Anaesthesiology, ${ }^{4}$ Clinical Data Processing, \\ Sahlgrenska Hospital, S-413 45 Gothenburg, Sweden.
}

\begin{abstract}
When performing forward trunk flexion, cervical cord injured (CCI) patients exhibit continuous and high EMG activity in the diaphragm and elevated abdominal pressures. This study addressed the question whether the trunk flexion manoeuvres cause such a high force development in the diaphragm that this muscle shows EMG signs of fatigue.

Six patients with complete cervical cord lesions were tested sitting in their own wheelchairs. The tension-time indices obtained when patients were sitting in a relaxed position were moderately to markedly higher than in normal subjects. The force developed during trunk flexion averaged $30 \%$ of the maximal transdiaphragmatic pressure and was accompanied by clear EMG findings of diaphragmatic fatigue in all patients except one.

The acute diaphragmatic load in certain CCI patients may well produce ischaemia and increase the risk of tissue impairment. Therefore, there appears to be a need for differing strategies in the short and in the long term treatment of CCI patients; longitudinal evaluation of main diaphragmatic function may be useful for an adequate amount of respiratory muscle training.
\end{abstract}

Key words: diaphragmatic fatigue; cervical spinal cord injury; electromyography; trunk flexion.

\section{Introduction}

In patients with complete cervical cord lesions (CCI) the diaphragm obviously has a dual function - to perform inspiratory work and to maintain balance when patients bend forward from a sitting position. ${ }^{1}$ During forward flexion, patients exhibit continuous and high electromyographic (EMG) activity in the diaphragm and also elevated abdominal pressures.

Gross $e t \mathrm{al}^{2}$ showed that fatiguing of the diaphragm as measured by transthoracic quantification of the EMG signal spectrum occurs at lower inspiratory loads in CCI patients than in healthy individuals. How the diaphragm is affected by its increased contractile force during forward bending has not been analysed.

\footnotetext{
${ }^{*}$ Correspondence.
}

The aim of this study was to determine whether postural loading of the diaphragm during trunk flexion can cause signs of fatigue in the diaphragmatic EMG signal spectrum.

\section{Method}

\section{Patients and methods}

All participants in this study had given their informed consent and the study was approved by the Ethical Committee of the University of Gothenburg. Six male CCI patients with functionally complete lesions were investigated sitting in their wheelchairs. Patient characteristics are given in Table I. Before the test, the patients ate a small standardised breakfast.

Respiratory flow was measured at the mouth with a pneumotachograph (Jaeger Screenmate, $1 / \mathrm{E} 0586$, resistance $36 \mathrm{~Pa} / \mathrm{l} / \mathrm{s}$ ) hanging from a rigid lever in a $40 \mathrm{~cm}$ long 
elastic band. Volume was obtained by integration of flow. A modified ${ }^{3}$ quadruplelumen Swan Ganz Pacing-TD catheter (93-200H-7F, American Edwards Laboratories) $110 \mathrm{~cm}$ in length was introduced via the nose to a distance of $80 \mathrm{~cm}$. Gastric and oesophageal pressures (Pga and Pes) were registered by two latex balloons, each $10 \mathrm{~cm}$ in length and $3.5 \mathrm{~cm}$ in circumference, attached to the catheter which, in turn, was connected to two differential pressure transducers (SCM-Screenmate-spezial, Erich Jaeger $\mathrm{GmbH} \& \mathrm{Co}$ ), with atmospheric pressure as reference. The oesophageal and abdominal ballons were emptied until a negative pressure of $2 \mathrm{kPa}$ was obtained and then inflated with 0.5 and $2.5 \mathrm{ml}$ of air, respectively ${ }^{4}$ The transdiaphragmatic pressure (Pdi) was calculated as the difference between iso-time gastric and oesophageal pressures. Correction for the filtering properties of the catheter was made by enhancement of the high-frequency components of the pressure signals.

Two cobalt electrodes (Elgiloy ${ }^{\mathrm{TM}}$ ) situated $15 \mathrm{~mm}$ apart registered the diaphragmatic EMG signals (EMGdi). To maintain the distance between the EMG electrodes and the diaphragm, an anchoring balloon, $3 \mathrm{~cm}$ in length and $3.5 \mathrm{~cm}$ in circumference, was attached $1.5 \mathrm{~cm}$ distally to the most distal EMG electrode on the catheter and balanced by a small weight which was attached proximal to the nostrils. The EMGdi signals were amplified (Medelec AA6 Mk III with preamplifier) and band pass filtered with cutoff frequencies of 8 and $800 \mathrm{~Hz}$ respectively.

Flow, oesophageal and gastric pressure signals were collected with a sampling frequency of $125 \mathrm{~Hz}$ and the EMGdi signals with $2 \mathrm{KHz}$. All signals were processed in a digital computer (PDP-11/70, Digital Equipment Corporation) and stored for subsequent analysis. A schematic description of the test set-up is presented in Figure 1.

\section{Protocol}

The maximal transdiaphragmatic pressure $\left(\mathrm{Pdi}_{\max }\right)$ was obtained by maximal inspiratory efforts against a closed airway. In an attempt to improve the patients' motivation, they were urged to overcome the highest accomplished Pdi visualised on a video monitor as a horizontal bar. At least 3 reproducible attempts were required.

To achieve a sustained trunk flexion, the patients were instructed to lift their arms and cross them on the chest and then bend forward to the outermost position that could be maintained without falling. They were instructed to remain in this position as long as possible. The sustained trunk flexion was repeated 3 times, but only the first one was used for EMG fatigue analysis; the other 2 were used to ascertain that EMG fatigue occurred at the same contraction levels during the second and third sustained trunk flexion. The maximal trunk angle during trunk flexion was measured using a gonio-

Table I Characteristics of the study patients

\begin{tabular}{lccccccc}
\hline $\begin{array}{l}\text { Patient } \\
\text { (no) }\end{array}$ & $\begin{array}{c}\text { Age } \\
\text { (year) }\end{array}$ & $\begin{array}{c}\text { Weight } \\
(\mathrm{kg})\end{array}$ & $\begin{array}{c}\text { Height } \\
(\mathrm{cm})\end{array}$ & $\begin{array}{c}\text { Time since } \\
\text { injury } \\
\text { (year) }\end{array}$ & $\begin{array}{c}\text { Level of } \\
\text { injury }\end{array}$ & $\begin{array}{c}\text { Pdi }_{\text {max }} \\
(\mathrm{kPa})\end{array}$ & $\begin{array}{c}\text { Loss of intercostal } \\
\text { EMG activity } \\
\text { (intercostal space) }\end{array}$ \\
\hline 1 & 31 & 72 & 193 & 10 & C5-C6 & 7.3 & $1-5$ \\
$2^{\text {a }}$ & 34 & 63 & 186 & 11 & C6 & 12.1 & $1-6$ \\
3 & 23 & 61 & 178 & 2 & C6-C7 & 6.0 & $1-5$ \\
4 & 25 & 62 & 170 & 3 & C6-C7 & 13.0 & $1-5$ \\
5 & 31 & 85 & 174 & 13 & C7-C8 & 14.7 & - \\
6 & 26 & 69 & 175 & 6 & C8-Th1 & 13.9 & $2-6$ \\
\hline
\end{tabular}

$\mathrm{Pdi}_{\max }=$ the maximal transdiaphragmatic pressure obtained during maximal inspiratory efforts with closed airway.

${ }^{a}$ Anterior rhizotomy Th12-S1 (6 years ago). 


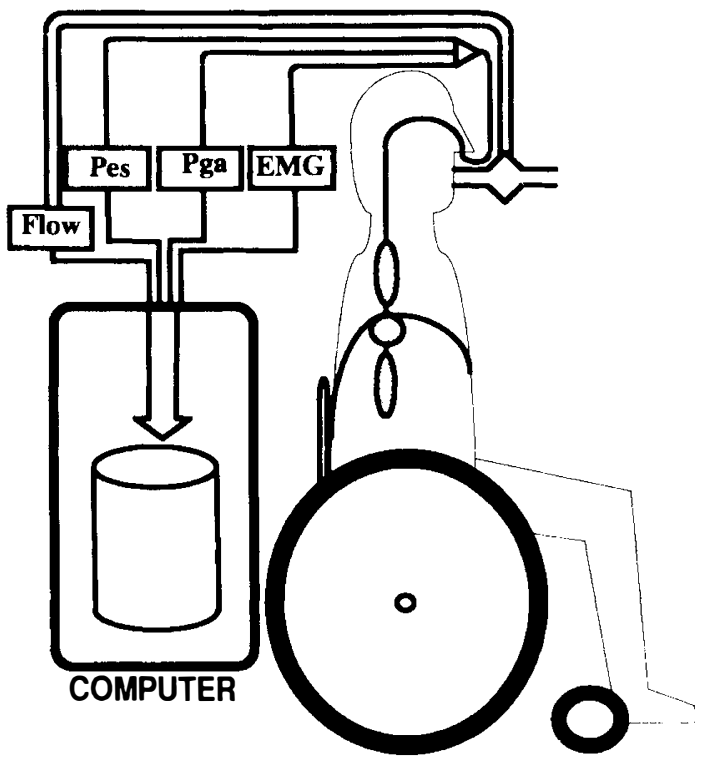

Figure 1 A description of the test situation.

meter, with the vertical plane as reference. To establish the influence of the passive increase in Pga during trunk flexion, 2 patients were examined in supported trunk flexion at $45^{\circ}$.

After the sustained trunk flexion, each patient underwent a qualitative determination of voluntary intercostal muscle EMG activity in the midclavicular line in the first to the seventh intercostal space parasternally. The EMG electrode was positioned successively in each intercostal space and at each level the patient was asked to make at least 3 maximal inspirations. Total absence of phasic inspiratory myoelectric activity was used as a criterion of loss of voluntary muscle activity.

\section{Data processing and analysis}

The EMGdi signals were visualised on a video monitor and continuous sequences of $255 \mathrm{~ms}$ were manually collected where clear EMGdi signals were present and no cardiac QRS complex was observed. All the EMGs which were free of ECG were collected. For each selected sequence, EMGdi signal strength was calculated as the root mean square values. Also, the centre frequency of the EMGdi (CFdi) and the mean Pdi, the latter subsequently referred to as Pdi, were calculated.

In order to avoid possible disturbances and individual signal strength differences of the EMGdi, sequences from 10 seconds of sitting at rest were used for normalisation according to the formula: $\triangle E M G d i$ $\equiv\left(E M G d_{\text {flex }_{1}}-\mathrm{EMGdi}_{\text {rest }}\right) / \mathrm{EMGdi}_{\text {rest }}$.

To quantify diaphragmatic EMG fatigue, we used power spectrum analysis of the $\mathrm{EMG}^{5}$. The validity of this method for detecting early signs of fatiguing work in the diaphragm has been demonstrated by Bellemare and Grassino. ${ }^{6,7}$ To verify the change in CFdi during the trunk flexion, we used linear regression and correlation analysis.

Increase of Pdi during trunk flexion $\left(\Delta \mathrm{Pdi}_{\text {flex }}\right)$ was calculated as the difference between the average Pdi during trunk flexion and the average end-expiratory Pdi during upright sitting at rest. Change in the relative transdiaphragmatic pressure was defined as change in the ratio between $\Delta \mathrm{Pdi}_{\text {flex }}$ and $\mathrm{Pdi}_{\text {max }}: \Delta \mathrm{Pdi}_{\text {flex }} / \mathrm{Pdi}_{\text {max }} \equiv$ $\left(\mathrm{Pdi}_{\text {flex }}-\mathrm{Pdi}_{\text {rest, and expir }}\right) / \mathrm{Pdi}_{\text {max }}$.

To define the diaphragmatic load at rest, the tension-time index (TTdi) ${ }^{6.7}$ was calculated for approximately 60 seconds of respiration at rest. In normal breathing, the development of fatigue during periodic muscle contraction strongly depends on the relative contractile force and the duty cycle, the latter represented by the inspiratory time divided by the time for the total respiratory cycle (Ti/Ttot). TTdi is calculated as the product of the relative transdiaphragmatic pressure $\left(\mathrm{Pdi} / \mathrm{Pdi}_{\max }\right)$ and the $\mathrm{Ti} /$ Ttot. Tension-time indices exceeding $0.15-0.20$ are considered to cause fatigue..$^{6.7}$

\section{Results}

Rest

In respiration at rest, the mean Pdi in all patients was $1.6 \mathrm{kPa}(\mathrm{SD} 0.61 \mathrm{kPa}$ ) giving a Pdi/Pdimax of 0.15 (SD 0.05). Ti/Ttot was 0.42 (SD 0.05) and the product of the relative diaphragmatic force and $\mathrm{Ti} / \mathrm{Tt}$ tot, TTdi, was 0.06 (SD 0.02). Individual values are given in Table II. 


\section{Sustained trunk flexion}

The average time of the sustained trunk flexion in all patients was 38.5 seconds (range 11-60 seconds), at a mean trunk flexion angle of $15^{\circ}$ (range $0-30^{\circ}$ ). All patients had an uninterrupted EMGdi activity throughout the period with a mean increase in $\triangle E M G d i$ of 1.2 (SD 0.44). Mean $\Delta \mathrm{Pdi}_{\text {flex }} / \mathrm{Pdi}_{\max }$ was 0.33 (SD 0.05), where Pdi was predominated by $\mathrm{Pga}$ with a Pga/Pdi ratio of 0.81 (SD 0.07). One patient only, no 5, exhibited a marked rise in the Pga/Pdi ratio, from 0.42 at rest to 0.91 during the sustained trunk flexion, possibly indicating a passive increase in Pga. In the remaining patients there was a less than $10 \%$ change in the Pga/Pdi ratio. In the 2 patients who performed supported trunk flexion to $45^{\circ}$, the end-expiratory Pga was 0.2 and $0.5 \mathrm{kPa}$, respectively.

Clear drops in CFdi were observed in all patients but one during the period of sustained trunk flexion. In this patient, no 5, CFdi increased during trunk flexion. The results obtained in each patient are presented in Table III. Despite the fact that thee EMGdi activity was continuous, all patients except no 2, holding his breath, showed an irregular pattern of respiratory flow. The median $\mathrm{Ti} / \mathrm{T}$ tot for all patients ranged from 0.28 to 1.0 with a large intraindividual fluctuation as described in Table III. Due to the variation in $\mathrm{Ti} / \mathrm{Tt}$ tot and the possibilities of a passive increase in $\Delta \mathrm{Pdi}_{\text {flex }}$ we did not calculate the product of the $\mathrm{Ti} /$ Ttot and the $\Delta \mathrm{Pdi}_{\text {flex }} / \mathrm{Pdi}_{\max }$.

In periods when all $\triangle$ EMGdi observations exceeded the baseline EMG activity (EMG signal strength at rest) by approximately $50 \%$ or more, there was frequently a clear decrease in CFdi. This is illustrated in Figure 2, showing 2 patients: patient no 2 (panel A) who held his breath throughout the trunk flexion with an $\triangle E M G d i$ range of 0.6-3.3 and a progressive decrease in CFdi; and patient no 5 (panel B) who had the least irregular $\mathrm{Ti} / \mathrm{T}$ tot, with an increase in CFdi, and an $\triangle$ EMGdi ranging from -0.1 to 2.8 .

All patients perceived the trunk flexion as increasingly strenuous and accompanied by difficulties in breathing. The sensation of loading was located in the chest and/or upper abdomen.

During trunk flexion, heart rate (HR) increased by a median of 8.0 beats/minute, (range $0-37$ beats/minute), as can be seen in Table III. No change in HR was registered in one patient, no. 6 , whose trunk flexion was discontinued after 11 seconds.

\section{Discussion}

Changes in CFdi have been described as being linked to changes in muscle length, distance to the signal source, recruitment of motor units etc. ${ }^{8}$ A correction of CFdi for pressure and flow parameters associated with muscle length, and EMGdi signal

Table II Results at rest, individual mean values of 60 second samples

\begin{tabular}{|c|c|c|c|c|c|c|}
\hline $\begin{array}{l}\text { Patient } \\
\text { (no) }\end{array}$ & $\begin{array}{c}\mathrm{Pdi} \\
(\because \mathrm{Pa})\end{array}$ & $\mathrm{Pdi} / \mathrm{Pdi}_{\max }$ & $\begin{array}{l}\mathrm{Ti} \\
(\mathrm{s})\end{array}$ & $\begin{array}{l}\text { Ttot } \\
(\mathrm{s})\end{array}$ & Ti/Ttot & TTdi \\
\hline 1 & 1.4 & 0.19 & 2.5 & 5.1 & 0.49 & 0.09 \\
\hline $2^{\mathrm{a}}$ & 2.7 & 0.23 & 1.4 & 3.4 & 0.41 & 0.09 \\
\hline 3 & 1.0 & 0.16 & 1.5 & 4.1 & 0.36 & 0.06 \\
\hline 4 & 1.5 & 0.12 & 2.4 & 5.2 & 0.48 & 0.06 \\
\hline 5 & 1.5 & 0.10 & 1.7 & 4.3 & 0.40 & 0.04 \\
\hline 6 & 1.2 & 0.09 & 1.2 & 3.3 & 0.37 & 0.03 \\
\hline All $\bar{X}$ & 1.6 & 0.15 & 1.8 & 4.2 & 0.42 & 0.06 \\
\hline SD & 0.6 & 0.05 & 0.6 & 0.8 & 0.05 & 0.02 \\
\hline
\end{tabular}

Pdi $=$ transdiaphragmatic pressure ie the difference between abdominal and oesophageal pressure. $\mathrm{Pdi} / \mathrm{Pdi}_{\max }=$ the transdiaphragmatic pressure expressed as a fraction of the maximal transdiaphragmatic pressure. $\mathrm{Ti}=$ inspiratory time. Ttot $=$ the time for one breath. TTdi $=$ tension time index for the diaphragm ie the product of $\mathrm{Pdi} / \mathrm{Pdi}_{\max }$ and $\mathrm{Ti} / \mathrm{T}$ tot.

a Anterior rhizotomy Th12-S1 (6 years ago). 
Table III Results of sustained trunk flexion

\begin{tabular}{|c|c|c|c|c|c|c|c|c|c|c|c|c|c|}
\hline \multirow{2}{*}{$\begin{array}{c}\text { Patient } \\
\text { (no) }\end{array}$} & \multirow{2}{*}{$\begin{array}{c}\text { Time of } \\
\text { trunk flex- } \\
\text { ion } \\
\text { (s) }\end{array}$} & \multirow[b]{2}{*}{$\bar{x}$} & \multicolumn{2}{|c|}{$\Delta$ EMGdi } & \multirow[b]{2}{*}{$\bar{X}$} & \multicolumn{2}{|c|}{$\Delta \mathrm{Pdi}_{\mathrm{max}} / \mathrm{Pdi}_{\max }$} & \multicolumn{2}{|c|}{$\mathrm{Ti} /$ Ttot } & \multirow{2}{*}{$\begin{array}{c}\Delta \mathrm{HR} \\
(\mathrm{Bpm})\end{array}$} & \multirow{2}{*}{$\begin{array}{c}\text { Time of } \\
\text { decay } \\
\text { CFdi } \\
\text { (s) }\end{array}$} & \multirow[t]{2}{*}{$\begin{array}{l}\text { Regression coefficient } \\
\text { CFdi vs time } \\
(\mathrm{Hz} / \mathrm{s})\end{array}$} & \multirow[t]{2}{*}{$\begin{array}{l}\text { Correlation } \\
\text { coefficient } \\
\text { CFdi vs time } \\
\text { (r) }\end{array}$} \\
\hline & & & SD & range & & SD & range & median & range & & & & \\
\hline 1 & 60 & $1 .()$ & 1.02 & $-0.5-3.8$ & 0.3 & 0.08 & (). $1-() .5$ & 0.6 & $(0.3-0.9$ & 11 & ()$-35$ & $-0.29(\mathrm{p}<0.03)$ & (0.34 \\
\hline $2^{a}$ & 27 & 1.6 & ().61 & $0.6-3.3$ & (). 4 & 0.05 & $(0.3-0.5$ & 1.0 & h & 9 & ()$-22$ & $-0.80(\mathrm{p}<0.0001)$ & 0.64 \\
\hline 3 & 42 & 1.1 & 0.86 & $-0.4-3.5$ & 0.3 & 0.07 & $(0.2-() .5$ & 0.5 & $(0.3-() .9$ & 7 & $(0-33$ & $-0.83(\mathrm{p}<0.00001)$ & 0.60 \\
\hline 4 & 57 & 1.9 & 0.99 & $0.2-6.2$ & (). 3 & $0 .(14$ & $(0.2-() . .3$ & 0.7 & $0.6-() .8$ & 4 & $15-45$ & $-0.84(\mathrm{p}<0.0(0)(0))$ & 0.72 \\
\hline 5 & 34 & 0.9 & 0.65 & $-0.1-2.8$ & 0.4 & 0.03 & $0.3-() .4$ & 0.5 & $(0.4-0.9$ & 37 & ()$-34$ & $0.26(\mathrm{NS})$ & 0.20 \\
\hline 6 & 11 & 0.8 & 0.44 & $(0.0-1.9$ & 0.3 & ().(1) & $0.2-() .4$ & 0.3 & (). $1-() .6$ & () & $2-11$ & $-2.88(\mathrm{p}<0.03)$ & 0.63 \\
\hline All $\bar{X}$ & 38.5 & 1.2 & & & 0.33 & & & 0.6 & & $8^{\circ}$ & & & \\
\hline SD & 18.6 & 0.44 & & & 0.05 & & & (). 24 & & & & & \\
\hline
\end{tabular}

$\Delta \mathrm{EMGdi}=$ change in EMG signal strength from rest to trunk flexion. $\Delta \mathrm{Pdi}_{\mathrm{fl}} / \mathrm{Pdi}_{\mathrm{mix}}=$ the change in Pdi from rest to trunk flexion expressed as a fraction of $\mathrm{Pdi}_{\text {max }}$. Ti/Ttot $=$ the ratio between inspiratory time and the total time for one breath. $\Delta \mathrm{HR}=$ change in heart rate from rest to end of the sustained trunk flexion. Time of decay in CFdi $=$ the time period when CFdi decreased and on which the regression analysis was performed.

"Anterior rhizotomy Th12-S1 (6 years ago), "Breatholding, "Median value. 

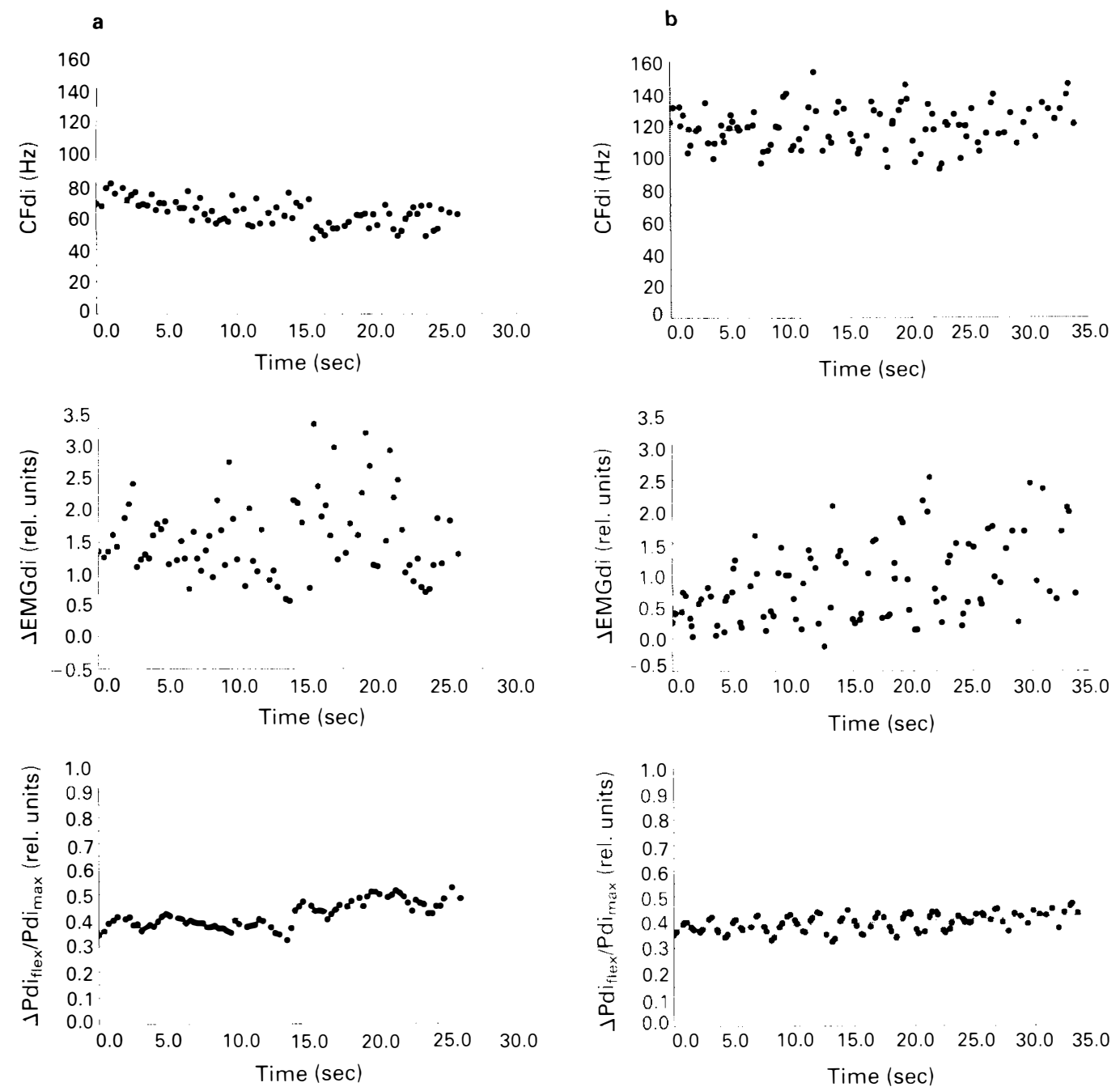

Figure 2a, b The time plots of the EMGdi centre frequency (CFdi) (upper panels), the $\triangle E M G d i$ (middle panels) and the $\Delta \mathrm{Pdi}_{\text {flex }} / \mathrm{Pdi}_{\max }$ ratio (lower panels) in patient no 2 (a) who holds his breath and no 5 (b) who have a median Ti/Ttot of 0.5 . Decrease in CFdi was frequently associated with a gap between the baseline EMGdi signal strength (EMGdi at rest) and the observed $\triangle$ EMGdi values at trunk flexion (a, middle panel). In panel (b), the rythmic variation in $\Delta \mathrm{Pdi}_{\mathrm{flex}} / \mathrm{Pdi}_{\max }$ tracings and frequent returns of $\Delta \mathrm{EMGdi}$ to its baseline level indicate that duty cycle governs diaphragmatic fatigue also when the breathing pattern consists of a continuous postural EMGdi-activity with a superimposed phasic respiratory activity.

characteristics (Sinderby et al, in manuscript), was performed to eliminate the influence of the factors listed above. This correction of CFdi did not affect present data.

The accuracy of calculating the relative diaphragmatic force as $\Delta \mathrm{Pdi}_{\text {flex }} / \mathrm{Pdi}_{\max }$ is uncertain when body position is changed due to the unknown influence of passive changes in Pga. Only one patient had a marked change in the $\mathrm{Pga} / \mathrm{Pdi}$ ratio at sustained trunk flexion and very small changes in Pga were observed in the 2 patients who had assistance in performing a 
passive trunk flexion. It should also be noted that trunk flexion in CCI patients is associated with such small changes of the trunk angle that they are not likely significantly to affect the pressure of the intraabdominal cavity. Thus, we interpreted the influence of passive changes in Pga on $\Delta \mathrm{Pdi}_{\text {flex }} / \mathrm{Pdi}_{\max }$ to be negligible. One explanation of the change of the $\mathrm{Pga} / \mathrm{Pdi}$ ratio from resting position to trunk flexion in patient no 5 could be reduced abdominal compliance, since this patient was more obese than the others.

The results of this study indicate that forward flexion of the trunk in sitting CCI patients elicits early signs of diaphragmatic fatigue, $\triangle E M G d i$ being more than doubled and $\Delta \mathrm{Pdi}_{\text {flex }} / \mathrm{Pdi}_{\text {max }}$ larger than 0.3. A convincing finding that verifies the relation between the decrease in CFdi and ischaemic diaphragmatic fatigue was the constantly high $\triangle$ EMGdi level, not returning to the baseline (EMGdi at rest), as depicted in Figure $2 a$. If $\triangle E M G d i$ repeatedly returned to the resting level, EMG fatigue may be avoided even though mean $\Delta \mathrm{Pdi}_{\text {flex }} / \mathrm{Pdi}_{\text {max }}$ and $\triangle E M G d i$ are high and the EMG activity is continuous as depicted in Figure $2 b$. These findings indicate that early signs of diaphragmatic fatigue are dependent on the duty cycle also when the breathing pattern consists of a continuous postural EMGdi activity with a superimposed phasic respiratory activity. During such conditions, it is unlikely that duty cycle can be calculated from flow. Hence, during contractions with continuous EMG activity, the critical level when the CFdi is expected to decrease seems to be when $\triangle E M G d i$ is constantly exceeding the resting level by $50 \%$ or more.

The unsupported sustained trunk flexion studied is not a representative activity of the patient group, except for balance and transfer exercises during the early phase of physical reactivation. Because the forward flexion in some patients induced levels of ischaemic diaphragmatic fatigue with contraction levels up to $50 \%$ of maximum, extreme endurance test of trunk flexion in, for example, wheelchair marathon races or in certain balance exercises such as basket ball may be injurious in the long term perspective. Recent findings shows that physical activity in CCI patients frequently produces diaphragmatic EMG fatigue. ${ }^{9}$ In some CCI patients the diaphragmatic force reserve to fatigue is severly reduced and comparable to that of patients with prior polio infection, the latter group being treated with intermittent positive ventilation. In contradiction to prior polio patients, CCI patients further increased their diaphragmatic force after EMG fatigue was evident ${ }^{9}$.

Provided the fatigued diaphragm is allowed to rest between repeated periods of strain, the concomitant metabolic and mechanical adaptation of muscle tissue should be similar to that seen after chronic training. In manoeuvres requiring balance maintenance, the repeated diaphragmatic contractions will add to the continuously increased basic tone from the training. One can only speculate on how such involuntary chronic training influences the diaphragmatic tissue, which normally functions by producing periodic contractions with very low power yields. ${ }^{6}$

Long term electrically induced tetanic contractions in animals are known to cause fibre type transformation. ${ }^{10-12}$ Borg et $a l^{13.14}$ showed that post-polio patients with excessive use of weak anterior tibial muscles exhibit a larger proportion of type I fibres in these muscles than polio patients without excessive muscle use. Similar adaption of diaphragmatic muscle fibres might also occur with time in very active CCI patients, but we are not aware of evidence of this.

What constitutes an adequate restitution period after excessive muscle work depends on the sort of fatigue imposed on the muscle, eg ischaemic local acidity, depletion of substrate or deficient central nervous induction. Braun et al $^{15}$ reported the recovery to be at least 24-48 hours after fatiguing phrenic stimulations of the diaphragm. In contrast, recovery after local ischaemic fatigue detected by high $\mathrm{HI} / \mathrm{LO}$ EMGdi registration is estimated to take place within a minute. ${ }^{7}$

TTdi during respiration at rest in the CCI patients of this study was 0.06 (SD 0.02, range $0.03-0.09$ ), which seems to exceed that of healthy individuals, for whom a value of 0.02 was reported. ${ }^{6}$ Bellemare and Grassino concluded that the patients who 
exhibited a TTdi index near 0.15 were impaired by a considerable reduction of their residual relative contractile force before the work of respiration caused fatigue.

Several studies, ${ }^{2,17}$ have demonstrated increased inspiratory force and/or improved endurance after short term respiratory training of both chronic and newly injured CCI patients using an inspiratory resistance model. The therapeutic value of additional training loads on muscles which already perform compensatory work for other paralysed muscles is rightfully debated. Such 'over-exercised' muscles may benefit more from rest and mechanical support, such as diaphragmatic unloading using a ventilator during the night. The hypothesis of muscular 'over-exercise' has been applied to cases where exhaustion of the diaphragm was not followed by satisfactory biochemical and mechanical restoration. ${ }^{15}$ The average relative contractile force $\left(\mathrm{Pdi} / \mathrm{Pdi}_{\max }\right)$ at rest in the present study was 0.15 (range 0.09-0.23), which implies that the load on the diaphragm in certain CCI patients may well produce ischaemia.

Bradley et al ${ }^{18}$ showed that normal subjects could not distinguish between short periods of fatiguing and non fatiguing contraction patterns of the diaphragm. Patients in the present study stated that they had difficulties in breathing while leaning forward and that the breathing felt strenuous, but none of those who showed signs of exhaustion or who held their breath felt pain. Others have also reported that the perception of strenuous breathing in tetraplegic patients may be reduced. ${ }^{19}$ However, patient no 5 who probably had unimpaired intercostal muscle function, seemed to be more subjectively affected by the trunk flexion than the others, even though he did not develop signs of diaphragmatic EMG fatigue.

The heart rate increase observed in the present study may be due to both nervous and mechanical mechanisms. The raised contractile force of the diaphragm may have caused a reduced vagal activity. Also, the change of HR may be elicited by the increased pressure in the abdomen compressing the large veins there and obstructing the venous reflux, thus diminishing cardiac refilling. In this way the heart rate increase may serve to compensate for smaller stroke volumes.

This study shows that patients with cervical cord lesions develop clear EMG signs of diaphragmatic fatigue when they bend forward. The perception of this fatigue may not be adequate. We emphasize the need for differing strategies in the short and long term treatment of CCI patients and suggest that longitudinal evaluation of their diaphragmatic function may be useful for the dosage of training and be important for the detection of unexpected late complications.

\section{Acknowledgements}

This study was supported by grants from the King Gustav V Foundation, the Swedish Association for Traffic and Polio Disabled, the Swedish Association for Neurologically Disabled, Folksam Insurance Company, Trygg Hansa Insurance Company, Glaxo Group Plc, Draco Ltd and the Greta and Einar Askers Research Foundation.

\section{References}

1 Sinderby C, Ingvarsson P, Sullivan L, Wickström I, Lindström L (in press) The role of the diaphragm in trunk extension in tetraplegia.

2 Gross D, Ladd HW, Riley EJ, Macklem PT, Grassino A (1980) The effect of training on strength and endurance of the diaphragm in quadriplegia. Am J Med 6: 27-35.

3 Javaheri S, Vinegar A, Smith J, Donovan E (1987) Use of a modified Swan-Ganz pacing catheter for measuring Pdi and diaphragmatic EMG. Pflügers Arch 408: 642-645.

4 Milic-Emili J (1984) Techniques in the Life Sciences, P4/II, Respiratory Physiology, P 412. Elsevier Scientific Publishers Ireland Ltd: 1-22.

5 Lindström L, Kadefors R, Petersén I (1977) An electromyographic index for localised muscle fatigue. J Appl Physiol 43: 750-754.

6 Bellemare F, Grassino A (1982a) Effect of pressure and timing of contraction on human diaphragm fatigue. J Appl Physiol; Respirat Environ Exercise Physiol 53: 1190-1195. 
7 Bellemare F, Grassino A (1982b) Evaluation of human diaphragm fatigue. J Appl Physiol; Respirat Environ Exercise Physiol 53: 1196-1206.

8 Lindström L, Magnusson R (1977) Interpretation of myoelectric power spectra: a model and its applications. Proceedings of the IEEE 65: 653-662.

9 Sinderby C, Weinberg J, Lindström L, Grassino AE (submitted for publication) Respiratory muscle force reserve in patients with cervical cord injuries and with prior polio infection.

10 Pette D, Smith ME, Staudte HW, Vrbova' G (1973) Effects of long-term electrical stimulation on some contractile and metabolic characteristics of fast rabbit muscles. Plügers Arch 338: 257-272.

11 Salmons S, Vrbova' G (1969) The influence of activity on some contractile characteristics of mammalian fast and slow muscles. $J$ Physiol (Lond) 210: 535-549.

12 Sreter FA, Gergely J, Salmons S, Romanul FCA (1973) Synthesis by fast muscle of myosin characteristic of slow muscle in response to long-term stimulation. Nature (New Biol) 241: 17- 19.

13 Borg K, Borg J, Edström L, Grimby L (1988) Effect of excessive use of remaining muscle fibers in prior polio and LV lesion. Muscle Nerve 11: 1219-1230.

14 Borg K, Borg J, Dhoot GK, Edström L, Grimby L, Thornell LE (1989) Motor neuron firing and isomyosin type of muscle fibres in prior polio. J Neurol Neurosurg Psychiatry 52: 1141-1148.

15 Braun NMT, Faulkner J, Hughes RL, Roussos C. Sahgal V (1983) When should respiratory muscles be exercised. Chest 84: 76-78.

16 Fugl-Meyer AR (1971) A model for treatment of impaired ventilatory function in tetraplegic patients. Scand J Rehab Med 3: 168-177.

17 Lerman RM, Weiss MS (1987) Progressive resistive exercise in weaning high quadriplegics from the ventilator. Paraplegia 25: 130-135.

18 Bradley TD, Chartrand DA, Fitting JW, Killian KJ, Grassino A (1986) The relation of inspiration effort sensation to fatiguing patterns of the diaphragm. Am Rev Respir Dis 134: 1119-1124.

19 Gottfried SB, Leech I, DiMarco AF, Zaccardelli W, Altose MD (1984) Sensation of respiratory force following low cervical cord transection. J Appl Physiol; Respirat Environ Exercise Physiol 57: 989-994. 